\title{
INFLUÊNCIA DAS VARIAÇÕES ESTACIONAIS E PROFUNDIDADE DE SEMENTES NO SOLO NA DORMÊNCIA E GERMINAÇÃO EM Rumex crispus L. ${ }^{1}$
}

\author{
RICARDO CARMONA ${ }^{2}$
}

RESUMO

\begin{abstract}
Sementes de Rumex crispus L. foram enterradas às profundidades de 1 e $10 \mathrm{~cm}$ no solo e coletadas a intervalos regulares durante dois anos. As sementes coletadas foram testadas a $10^{\circ}$ e $20^{\circ} \mathrm{C}$ no escuro; a $5 / 25^{\circ} \mathrm{C}$ (16/8 horas) com $10 \mathrm{mM}$ de nitrato de potássio e luz; e num regime de temperaturas alternadas correspondendo às mínimas e máximas médias do solo (MMTS), a profundidade de $1 \mathrm{~cm}$ durante 6 dias anteriores a cada coleta. Os tratamentos MMTS foram executados no escuro com $1 \mathrm{mM}$ de nitrato de potássio ou uma mistura de estimulantes de germinação consistindo de nitrato de potássio, tiuréia, etefon, azida de sódio e peróxido de hidrogênio. A perda de viabilidade das sementes no solo durante o período estudado foi praticamente desprezível. As sementes mostraram ciclos de dormência ao longo do ano, quando as baixas temperaturas do solo superaram a dormên-
\end{abstract}

cia primária e parale la mente induzi ram do rmên cia secundária, a qual por sua vez era superada pela elevação da temperatura. A dormência decresceu no segundo ano. $\mathrm{O}$ ambiente a $10 \mathrm{~cm}$ favoreceu a perda de dormência, entretanto o decréscimo de sementes devido à germinação in situ foi mais acentuado a $1 \mathrm{~cm}$ de profundidade. A mistura química foi mais eficiente quando a dormência era mínima e as temperaturas do solo eram mais promotivas, o que correspondeu - ao período quente do ano (da primavera ao outono). Discutem-se as implicações destes resultados na interpretação do comportamento ecológico da espécie e na adoção de práticas de manejo de bancos de sementes da invas ora no solo.

Palavras-chave: controle, decréscimo, estimulantes, língua-de-vaca.

\section{ABSTRACT \\ The effects of seasonality and burial depth of seeds in the soil on the dormancy and germination of Rumex crispus $\mathbf{L}$.}

Rumex crispus L. seeds were buried at 1 and $10 \mathrm{~cm}$ depth in the soil and retrieved at regular intervals during two years. Retrieved seeds were tested at $10^{\circ}$ and $20^{\circ}$ in darkness; at $525^{\circ} \mathrm{C}(16 / 8$ hours $)$ with $10 \mathrm{mM}$ potassium nitrate and light; and at an alternating temperature regime corresponding to the minimum and maximum soil temperatures (MMTS) at a depth of $1 \mathrm{~cm}$ during the six days prior to each retrieval. MMTS treatments were carried out in darkness with either $1 \mathrm{mM}$ potassium nitrate or a cocktail of dormancy relieving chemicals consisting of potassium nitrate, thiourea ethephon, sodium azide and hydrogen peroxide. There was no appreciable loss of seed viability in the soil during the study period. The seeds showed dormancy cycles in the soil throughout the year, where low soil temperatures relieved primary dormancy and induced secondary dormancy, which in turn was relieved by high temperatures. There was a year-to-year reduction in seed dormancy. The environment at $10 \mathrm{~cm}$ favoured loss of dormancy, however the depletion due to in situ germination was faster at $1 \mathrm{~cm}$. The chemical mixture was more effective when dormancy was minimal and the soil temperatures were more promotive, which coincided to the warm period of the year (from spring to autumn). These results are discussed in terms of the interpretation of the ecological behaviour of this species in the field and the adoption of practices of management of seed banks in the soil.

Additional index words: control, depletion, dock, stimulants. 


\section{INTRODUÇÃO}

R. crispus é uma importante planta daninha perene bastante disseminada principalmente em regiões temperadas (Foster, 1989). No Brasil infesta pastagens, pomares, jardins, culturas anuais, beira de estradas e terrenos baldios, desde Minas Gerais e Mato Grosso do Sul até o Rio Grande do Sul (Lorenzi, 1991). Uma única planta pode produzir até 60.000 sementes por ano, que podem permanecer dormentes no solo por mais de 80 anos (Lorenzi, 1991). Vários mecanismos garantem a manutenção de bancos de sementes no solo (Carmona, 1992).

Algumas espécies mostram fluxos de emergência no campo em resposta a alterações no ambiente ou na dormência de sementes (Karssen, 1982; Murdoch, 1982; Van Assche \& Vanlerberghe, 1989). A emergência de Rumex spp ocorre principalmente durante a primavera e outono na Inglaterra (Roberts \& Neilson, 1980) e Bélgica (Van Assche \& Vanlerberghe, 1989), ocorrendo mais cedo em Portugal, de janeiro a fevereiro e de agosto a setembro, devido às temperaturas mais altas do solo (Caixinhas, 1984).

Não está claro para a maioria das espécies, inclusive $R$. crispus, se os fluxos de emergência resultam apenas de alterações ambientais ou se a dormência de sementes também afeta este processo. Van Assche \& Vanlerberghe (1989) verificaram ciclos anuais de dormência em sementes enterradas de R. obtusifolius L., enquanto Baskin \& Baskin (1985a) concluíram que sementes recém-coletadas de $R$. crispus não apresentaram dormência e permaneceram como tal quando expostas a variações estacionais de temperatura no solo.

A identificação de ciclos de dormência de sementes no solo apresenta um importante papel na interpretação do comportamento ecológico da espécie no campo. Além disto ajuda no desenvolvimento de técnicas visando acelerar a redução de bancos de sementes de plantas invasoras. A estimulação de germinação no campo, através de práticas como aplicação de compostos químicos e preparo do solo, deve ser mais intensa quando a dormência é mínima. Esta hipótese é testada no presente trabalho.

Além das variações ambientais estacionais, a profundidade no solo afeta o microclima ao qual as sementes são expostas e, em consequiência, a taxa de decréscimo. Quanto mais próximas à superfície maiores a exposição à luz, oscilações de temperatura e umidade diárias que podem afetar a germinação e longevidade de sementes (Roberts, 1981). A concentração de nitrato, um estimulante de germinação em várías espécies (Brasil, 1992), também é normalmente maior próximo à superfície (Roberts, 1981). A probabilidade de ataque por predadores patógenos também aumenta com a proximidade da superfície. Todos estes fatores devem afetar a persistência de sementes de espécies sensíveis aos mesmos no solo, alterando a taxa de decréscimo a distintas profundidades.

Os objetivos do presente trabalho são de avaliar: a) a influência das variações estacionais e da profundidade no solo na germinação, dormência e longevidade de sementes de $R$. crispus; b) as condições nas quais estas sementes são mais sensíveis à aplicação de estimulantes de germinação.

\section{MATERIAL E MÉTODOS}

Utilizaram-se sementes coletadas manualmente em outubro de 1988 em infestação natural na Fazenda Lane End, próxima a Reading, sul da Inglaterra. Após secagem por 72 horas, em ambiente a $15 \%$ de umidade relativa e $15-20^{\circ} \mathrm{C}$, o material sofreu trilha manual, peneiração e sopração, descartando-se sementes vazias e material inerte. As sementes limpas foram secadas até $10 \%$ umidade no mesmo ambiente descrito e armazenadas dentro de sacos impermeáveis de alumínio a $-20^{\circ} \mathrm{C}$.

Em 25/11/1988, 400 sementes por saco de poliéster foram enterradas no solo às profundidades de $1 \mathrm{e} 10 \mathrm{~cm}$, na Fazenda Sonning próxima a Reading. O solo era arenoso, da série Rowland, com boa drenagem (Kay, 1936), apresen tando $\mathrm{pH}=6.2$, potássio $=55 \mathrm{ppm}$, fósfom=85 ppm e magnésio $=77 \mathrm{ppm}$.

Os sacos $(5 \times 5 \mathrm{~cm})$ eram feitos de malha com aproximadamente 374 aberturas triangulares.cm ${ }^{2}$ (34 x 11 aberturas. $\left.\mathrm{cm}^{-1}\right)$. Adotou-se o delineamento experimental de blocos casualizados arranjado em parcelas subdivididas com três repetições, sendo que as parcelas principais constituíram as épocas de coleta e as subparcelas a profundidade. O tamanho das parcelas foi de $50 \times 50 \mathrm{~cm}$, divididas em duas subparcelas de 25 x $50 \mathrm{~cm}$. As coletas foram feitas a intervalos de seis semanas até o dia 24/12/1990 de ambas profundidades.

A área experimental foi mantida livre de vegetação durante todo o período através de pulverizações mensais de abril a outubro com 200 1.ha- ${ }^{1}$ de Paraquat a $2.5 \%$ (v/v) (Gramoxone 100). A temperatura do solo a ambas profundidades foi registrada automaticamente a cada 10 minutos durante todo o período experimental, usando sensores na área. O sistema de registro e processamento de dados usou microcomputador BBC com programa desenvolvido especialmente para esta finalidade (Murdoch, 1985; Murdoch \& Allen, 1986).

Os sacos foram coletados no escuro (à noite), envolvidos em papel alumínio, e os testes de germinação instalados imediatamente, em sala escura, adaptada com luz verde Ilford de baixa intensidade (G907), a uma temperatura similar à do solo na época de coleta. Estes procedimentos visaram minimizar qualquer efeito da coleta e manuseio na dormência de sementes.

As plântulas encontradas nos sacos eram descartadas e as sementes divididas em porções aproximadamente iguais para os testes de germinação. Os testes foram conduzidos em placas de petri forradas com duas folhas de papel Whatman Grade 181 umedecidas com $4.5 \mathrm{ml}$ de água deionizada ou solução química conforme o tratamento. As placas eram acondicionadas dentro de sacos plásticos transparentes para evitar evaporação. Nos testes com luz utilizou-se luz contínua proveniente de duas lâmpadas fluorescentes de $20 \mathrm{~W}$ cada, o que correspondeu a uma foto-dose entre 0.1-0.9 mol.m ${ }_{2}^{2} \cdot \mathrm{d}^{-1}$ alcançando as sementes. A germinação no escuro foi obtida através do envolvimento das placas com duas folhas de papel alumínio. A duração dos testes foi de quatro semanas. A viabilidade das sementes foi avaliada pelo teste de germinação a $5 / 25^{\circ} \mathrm{C}(16 / 8$ horas), com $10 \mathrm{mM}$ de nitrato de potássio e luz (Totterdell \& Roberts, 1980). As sementes foram também testadas a $10^{\circ}$ e $20^{\circ} \mathrm{C}$ em água no escuro e num regime tentando simular as máximas e mínimas temperaturas do solo no período de coleta (MMTS). 
Os testes em MMTS foram feitos no escuro, utilizando $1 \mathrm{mM}$ nitrato de potássio (concentração média no solo no local do experimento - Murdoch, 1982) ou uma mistura estimulante de germinação contendo: $20 \mathrm{mM}$ nitrato de potássio, $4 \mathrm{mM}$ tiuréia, $300 \mathrm{mg} / \mathrm{I}$ etefon, $1 \mathrm{mM}$ azida de sódio e $10 \mathrm{mM}$ peróxido de hidrogênio (Carmona, 1992). Os regimes MMTS foram calculados com dados de temperatura coletados a $1 \mathrm{~cm}$ de profundidade nos seis dias prévios a cada coleta. Correspondiam às mínimas e máximas temperaturas médias diárias neste período. $\mathrm{O}$ período diário em cada temperatura era calculado através do tempo médio acima e abaixo da temperatura mediana diária. Estes regimes visaram simular os extremos de temperatura aos quais as sementes estavam submetidas no campo (Tabela 1).

O déficit de água acumulado no solo durante o período do experimento foi calculado através da diferença entre a precipitação total na área e a evapotranspiração potencial para gramado verde fechado (Neil Smith, comunicação pessoal, 1991).

O decréscimo de sementes foi estimado pela diferença entre as sementes iniciais em cada saco e o número de sementes viáveis coletadas. Os resultados do teste de germinação foram expressos como porcentagem do número de sementes cheias em cada teste.

\section{RESULTADOS E DISCUSSÃO}

Ciclos de indução e superação de dormência foram identificados em sementes germinadas a 10 e $20^{\circ} \mathrm{C}$ (Fig.1). A
TABELA 1. Temperaturas e termoperíodos de regimes MMTS nas várias coletas.

\begin{tabular}{|c|c|c|c|c|}
\hline \multirow{2}{*}{$\begin{array}{c}\text { Data de } \\
\text { coleta }\end{array}$} & \multicolumn{2}{|c|}{ Temperatura $\left({ }^{\circ} \mathrm{C}\right)$} & \multicolumn{2}{|c|}{ Tempo (h:min) na temp. } \\
\hline & mínima & máxima & mínima & máxima \\
\hline $15 / 05 / 89$ & 11.0 & 22.0 & $13: 00$ & $11: 00$ \\
\hline 29/06/89 & 19.0 & 37.0 & $14: 00$ & $10: 00$ \\
\hline 07/08/89 & 15.0 & 29.5 & $13: 00$ & $11: 00$ \\
\hline $18 / 09 / 89$ & 13.0 & 19.0 & $14: 30$ & $9: 30$ \\
\hline $30 / 10 / 89$ & 4.5 & 11.5 & $14: 00$ & $10: 00$ \\
\hline $11 / 12 / 89$ & -3.6 & 1.9 & $14: 00$ & $10: 00$ \\
\hline $22 / 01 / 90$ & 1.9 & 7.7 & $14: 00$ & $10: 00$ \\
\hline 05/03/90 & 1.2 & 8.2 & $14: 00$ & 10:00 \\
\hline $04 / 05 / 90$ & 11.3 & 30.5 & $13: 00$ & $11: 00$ \\
\hline $28 / 05 / 90$ & 10.5 & 29.5 & $13: 30$ & $10: 30$ \\
\hline 07/07/90 & 12.9 & 27.7 & $16: 00$ & $8: 00$ \\
\hline $20 / 08 / 90$ & 16.9 & 33.6 & $14: 00$ & $10: 00$ \\
\hline $01 / 10 / 90$ & 9.0 & 21.0 & $14: 00$ & $10: 00$ \\
\hline $12 / 11 / 90$ & 2.8 & 11.4 & $17: 00$ & $7: 00$ \\
\hline $24 / 12 / 90$ & 1.0 & 4.2 & $15: 30$ & $8: 30$ \\
\hline 04/02/91 & 0.1 & 2.1 & $17: 00$ & $7: 00$ \\
\hline $18 / 03 / 91$ & 6.2 & 14.5 & $15: 00$ & $9: 00$ \\
\hline $29 / 04 / 91$ & 2.7 & 19.0 & $14: 30$ & $9: 30$ \\
\hline $10 / 06 / 91$ & 11.6 & 18.1 & $14: 30$ & $9: 30$ \\
\hline
\end{tabular}

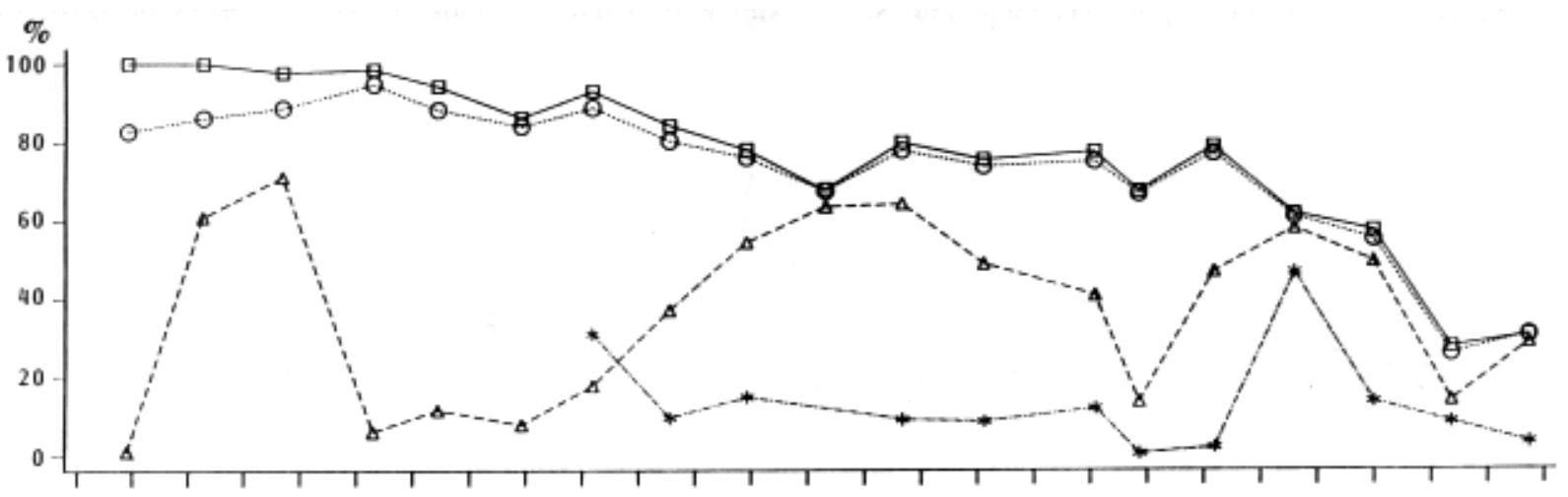

(a)

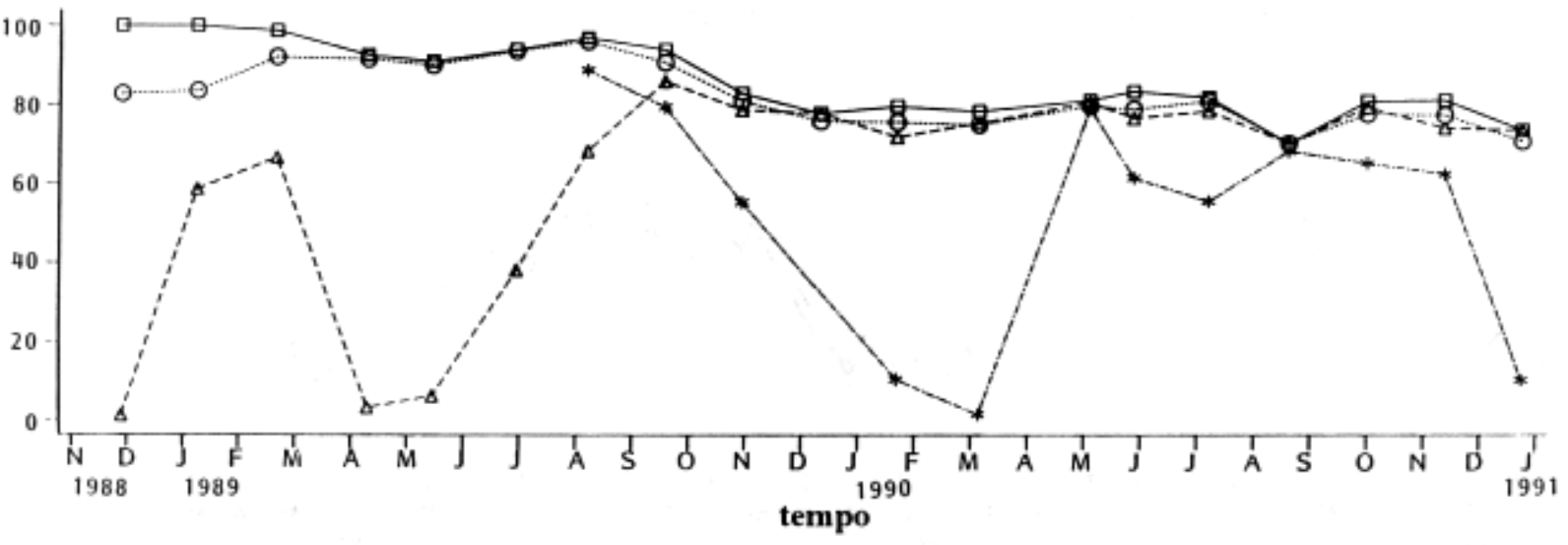

(b)

FIG. 1 - Decréscimo de sementes de $R$. crispus a 1 (a) e 10 (b) $\mathrm{cm}$ de profundidade no solo e germinaçảo de sementes remanescentes, onde $(\square)$ representa a porcentagem de sementes cheias coletadas. $\mathbf{A}$ germinação foi testada a $5 / 25^{\circ} \mathrm{C}(16 / 8 \mathrm{~h})$ com luz e nitrato $(\mathrm{O})$, e em água e no escuro a $20^{\circ} \mathrm{C}(\Delta)$ e $10^{\circ} \mathrm{C}(*)$. 
genminação a $20^{\circ} \mathrm{C}$ em sementes coletadas de ambas profundidades aumentou de novembro a fevereiro, decaindo em seguida (Fig.1). Isto indica perda de dormência primária logo após enterrio seguida de indução de dormência secundária. Totterdell \& Roberts (1979) observaram que baixas temperaturas em laboratório reduzem a dormência primária em sementes de $R$. crispus e paralelamente induzem dormência secundária nas mesmas. Os resultados do presente trabalho comprovam em campo as observações destes autores em condições controladas. $\mathrm{O}$ aumento da temperatura do solo durante o verão de 1989 (Fig.2) foi seguida pela redução na dormência secundária estimada pelo teste a $20^{\circ} \mathrm{C}$. Entretanto, esta redução foi afetada pela profundidade sendo gradual e lenta de abril a dezembro a $1 \mathrm{~cm}$, enquanto a $10 \mathrm{~cm}$ quase todas sementes germinavam já em setembro.

Os testes de germinação a $10^{\circ} \mathrm{C}$, que começaram em agosto de 1989, também identificaram um ciclo de dormência semelhante durante o segundo ano no solo, especialmente em sementes coletadas a $10 \mathrm{~cm}$ (Fig.1). As sementes coletadas a $1 \mathrm{~cm}$ germinaram pouco nesta temperatura, exceto na coleta de agosto, após ter sido registrada a temperatura mais elevada no campo (Fig.2). A habilidade de sementes coletadas a $10 \mathrm{~cm}$ de germinar nesta temperatura era alta em setembro de 1989, depois decresceu com as baixas temperaturas do solo até março de 1990, após o que o aumento nas temperaturas foi seguido pelo aumento na germinação a $10^{\circ} \mathrm{C}$. Depois a germinação nesta temperatura decresceu outra vez em dezembro de 1990, iniciando-se outro ciclo. Estes dados confirmam a indução de dormência secundária por baixas temperaturas e superação por altas temperaturas.
De acordo com Baskin \& Baskin (1985b, 1989), durante a transição entre dormência e não-dormência as sementes adquirem a habilidade de germinar num espectro mais amplo de condições ambientais. A partir dos presentes resultados, sementes de $R$. crispus adquirem a habilidade de germinar primeiro a $20^{\circ}$ e depois a $10^{\circ} \mathrm{C}$ (Fig.1). Portanto, a temperatura de $20^{\circ} \mathrm{C}$ deve ser mais adequada para testar variações em dormência em sementes mais dormentes e $10^{\circ} \mathrm{C}$ em sementes menos dormentes.

Estas observações são importantes para a interpretação da dinâmica de germinação desta espécie no campo. Quando novas sementes caem no solo no outono, algumas plântulas podem emergir imediatamente (Roberts \& Neilson, 1980) desde que não apresentem profunda dormência primária. $\mathrm{O}$ abaixamento da temperatura no solo durante o inverno previne a germinação, reduz a dormência primária e em paralelo induz dormência secundária. $\mathrm{O}$ aumento de temperatura da primavera em diante ocasiona a diminuição da dormência secundária. Se a dormência cai o suficiente previamente ao próximo inverno e o ambiente é ainda favorável, a germinação pode ser desencadeada. Alternativamente, a dormência secundária pode ser reinduzida por baixas temperaturas do solo, iniciando-se um novo ciclo. Assim o tempo de permanência da semente no solo vai depender do balanço entre dormência e ambiente.

Os ciclos de dormência descritos neste trabalho são semelhantes aos observados em Rumex obtusifolius na Bélgica (Van Assche \& Vanlerberghe, 1989), onde as temperaturas do solo assemelham-se às do local do experimento. Ambos trabalhos contradizem as conclusões de Baskin \&

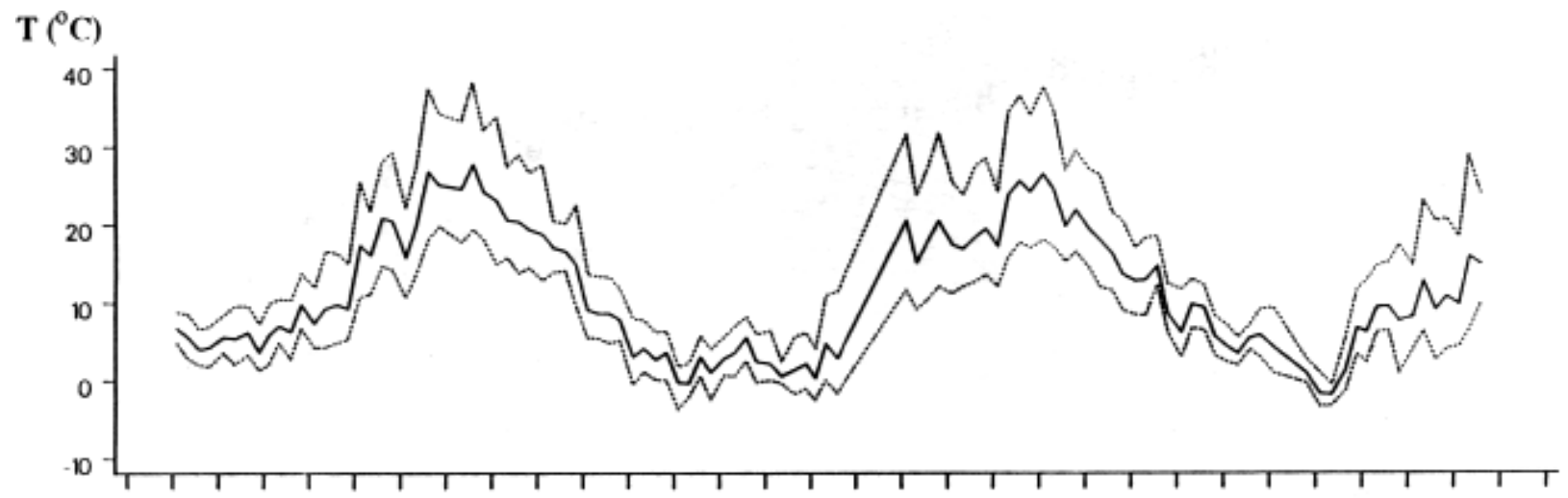

(a)

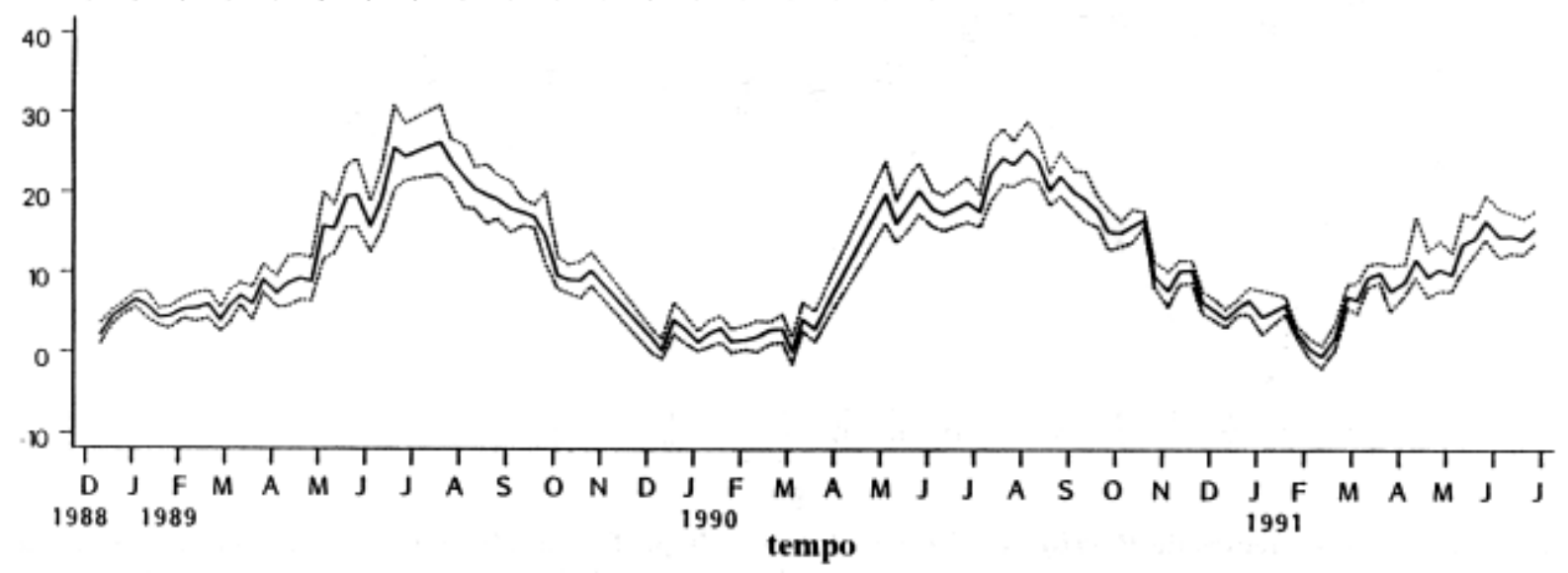

(b)

FIG. 2 - Temperaturas mínima, máxima (linhas descontínuas) e média (linha cheia) às quais as sementes ficaram naturalmente expostas a 1 (a) $\mathbf{e} 10 \mathrm{~cm}$ (b) no solo (médias semanais). 
Baskin (1985a) de que sementes de $R$. crispus chegam ao solo não dormentes e permanecem como tal quando expostas a variações estacionais de temperatura. As condições utilizadas por estes autores para testar as sementes coletadas (temperaturas alternadas com luz) eram provavelmente demasiado estimulatórias para detectar variações de dormência nesta espécie.

Apesar de a dormência declinar mais rapidamente a 10 do que a $1 \mathrm{~cm}$, o decréscimo de sementes no campo devido a germinação in situ ocorreu mais rápido a $1 \mathrm{~cm}$ de profundidade (Fig.1) durante o segundo ano. O pequeno decréscimo observado em 1989 deve ter sido causado pela tardia superação de dormência secundária, especialmente a $1 \mathrm{~cm}$. No segundo ano a máxima habilidade de germinar a $20^{\circ} \mathrm{C}$ foi atingida mais cedo, em agosto, quando as temperaturas do solo ainda eram favoráveis à germinação (Fígs.! e 2). O decréscimo ocorreu principalmente durante o outono do segundo ano. O decréscimo a ambas profundidades foi apenas ao redor de $20 \%$ de novembro 1988 a julho 1990, continuando em nível similar a $10 \mathrm{~cm}$ de profundidade até o fínal do estudo (dezembro 1990), enquanto a $1 \mathrm{~cm}$ apenas ao redor de $35 \%$ das sementes originais permaneceram até o fim. Outros estudos mostraram maior decréscimo devido a emergência no primeiro ano de ente rrio (Roberts \& Neilson, 1980). Provavelmente, a tardia data de enterrio e a dormência primária limitaram o decréscimo durante 1988 a $1 \mathrm{~cm}$ e em 1989 o decréscimo de dormência secundária foi muito tarde, já no outono, para permitir considerável germinação (Fig.!). Apesar da mais rápida superação de dormência a 10 $\mathrm{cm}$, o ambie nte não deve ter sido promotivo o suficiente nesta profundidade para que ocorresse grande germinação.

As sementes próximas à superfície estavam mais expostas à luz e flutuações na temperatura (Fig.3) e umidade, o que deve ter contribuído para o mais rápido decréscimo a 1 $\mathrm{cm}$. Estas condições são muito promotivas para germinação desta espécie (Taylorson \& Hendricks, 1972; Totterdell, 1974; Vincent \& Roberts, 1977; Vincent \& Cavers, 1978; Roberts, 1981; Roberts \& Totterde1l, 1981; Hand et al., 1982). Por outro lado, a mais rápida perda de dormência a 10 cm não pode ser explicada pelos mesmos fatores.
- A diferença em dormência entre as profundidades pode ajudar na interpretação ecológica do comportamento de campo desta espécie. Próximo à superfície do solo, onde o ambiente é mais promotivo, a dormência é mais importante para prevenir a germinação e distribui-la ao longo do tempo. $\mathrm{O}$ ambiente menos favorável à germinação a maiores profundidades torna a dormência mais dispensável à manutenção da espécie. A movimentação de sementes para profundidades mais superficiais poderia aumentar o fluxo imediato de emergência, trazendo sementes menos dormentes para um ambiente mais promotivo, o que explicaria o maior fluxo de germinação seguindo-se à movimentação de solo. Ambos os fatores, dormência e ambiente, poderiam agir em conjunto para promover ou inibir a germinação após perturbação do solo.

Como conseqüência prática destes resultados, pode-se prever que técnicas como o plantio direto, cultivo mínimo ou superficial devem aumentar a taxa de decréscimo de sementes de $R$. crispus recém-derrubadas, por mantê-las próximo à superfície. Por outro lado, o preparo convencional do solo deve aumentar a velocidade de decréscimo de sementes enterradas a maiores profundidades na medida em que as transporte para próximo da superfície.

A viabilidade das sementes coletadas permaneceu alta durante os dois anos confirmando a grande lo ngevidade desta espécie no solo (Fig.1). Algumas sementes (ao redor de $10-15 \%)$ não germinaram nestas condições no início do período, provavelmente devido à dormência primária. Assumiu-se que o decréscimo foi causado principalmente por germinação in situ, porque também não houve evidência de predação ou perda de viabilidade.

A germinação de sementes a MMTS também mostrou ciclos durante o ano (Fig.4). Entretanto, estes ciclos não se devem exclusivamente à dormência de sementes mas também ao efeito direto das diferentes temperaturas na germinação. A germinação nestas temperaturas foi sempre maior no período quente do ano (de abril a outubro) coincidindo com a maior eficiência da mistura química (Fig.4). As sementes germinaram melhor em MMTS durante o segundo ano, provavelmente devido a um declínio anual na dormência.

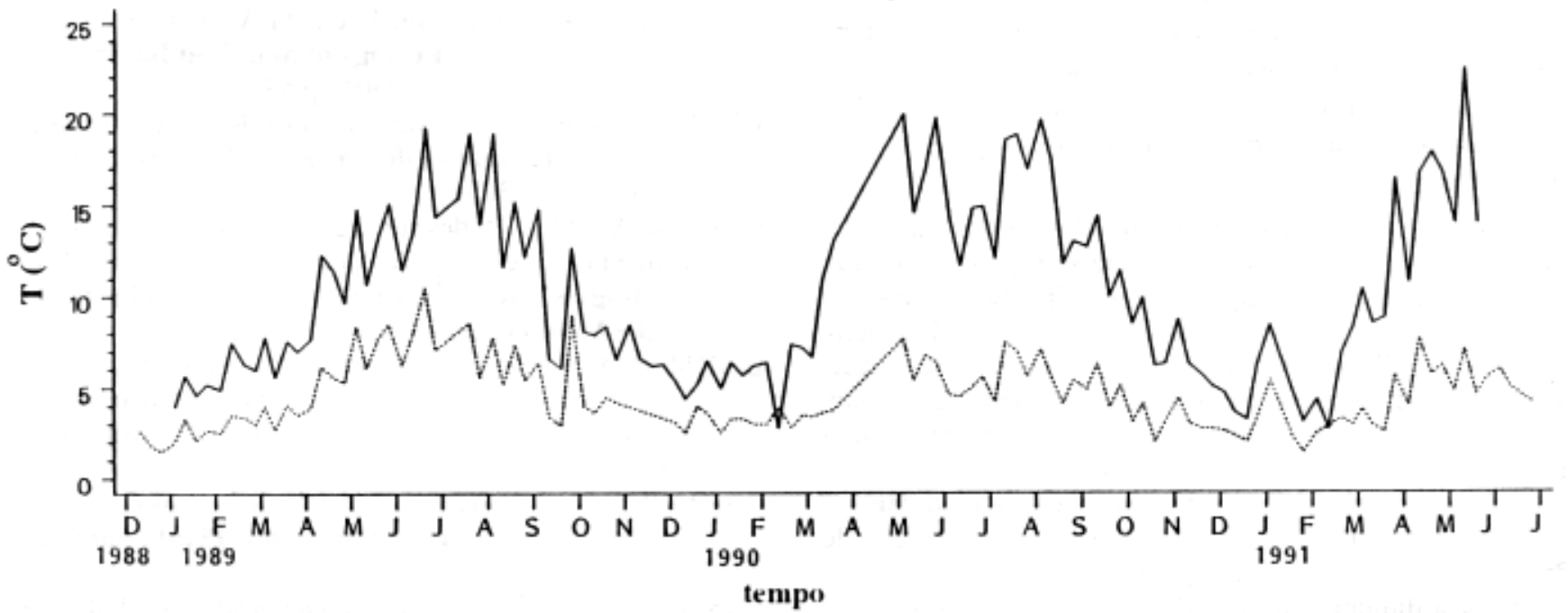

FIG. 3 - Flutuaçōes máximas de temperatura diária às quais as sementes ficaram expostas a $1 \mathrm{~cm}$ (linha cheia) $\mathrm{e} 10 \mathrm{~cm}$ (linha descontínua) no solo (médias semanais). 
Durante o primeiro ano, sementes coletadas a $10 \mathrm{~cm}$ mostraram maior germinação, confirmando a mais baixa dormência nesta profundidade.

Totterdell \& Roberts (1980) concluíram através de trabalho em laboratório que a temperatura máxima num regime promotivo deve ser pelo menos $15^{\circ} \mathrm{C}$ para germinação de sementes de Rumex spp. De fato, estes resultados mostram que a maior germinação foi obtida quando as temperaturas máximas do solo eram superiores a este nível (Tab.1, Fig.4).

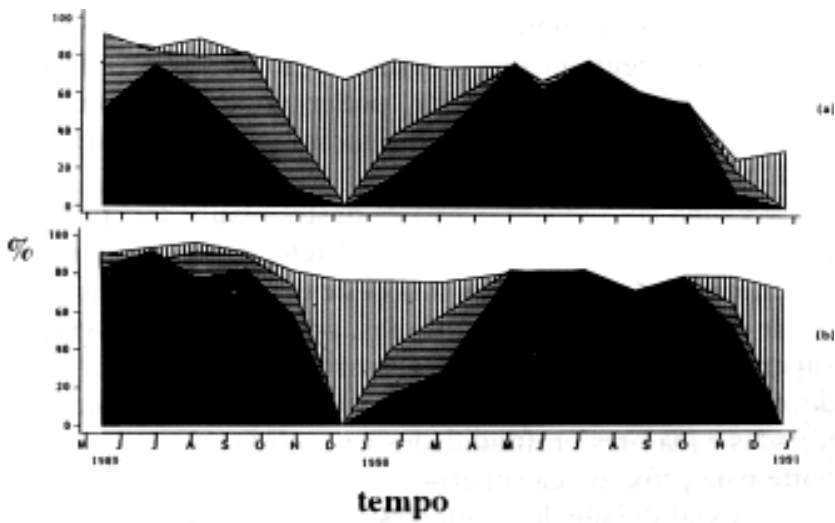

FIG. 4 - Germinação de sementes de $R$. crispus coletadas a 1 (a) e 10 (b) cm no solo nos regimes de temperatura MMTS (Tab.1) no escuro, onde: área negra= sementes germinadas em $1 \mathrm{mM}$ nitrato de potássio, linhas horizontais = germinaçāo adicional causada pela mistura química e linhas verticais= sementes que nâo germinaram em ambas condiçōes.

A mistura química promoveu germinação nesta espécie a MMTS, mesmo quando as sementes estavam mais dormentes e as temperaturas eram inibitórias, mas a germinação cessou completamente quando a temperatura caiu abaixo de $5^{\circ} \mathrm{C}$ na presença ou ausência de químicos (coleta em dezembro, Fig.4). Entretanto, a maior promoção ocorreu durante o período quente, quando as temperaturas do solo são mais favoráveis e a dormência é a mais baixa. De acordo com esses resultados, aplicações desta mistura no campo devem promover germinação de sementes dormentes desde que a temperatura média do solo não caia abaixo de $5^{\circ} \mathrm{C}$. A maior promoção deve ocorrer quando as temperaturas são mais favoráveis.

Apesar de a germinação em MMTS ter sido mais alta durante os meses ${ }^{p_{\text {iais }}}$ quentes do ano (junho a agosto), a emergência de Rumex spp ocorre principalmente durante a primavera e, em menor intensidade no outono, na Inglaterra (Roberts \& Neilson, 1980) e Bélgica (Van Assche \& Vanlerberghe, 1989). Aparentemente muitas sementes germinam no campo logo que a dormência decai da primavera ao outono e as temperaturas do solo são favoráveis à germinação. Deficiências hídricas que podem ser freqüentes durante o verão no local do experimento (Fig.5) e nas regiões do Brasil, onde a espécie ocorre, poderiam também restringir a emergência durante este período. Provavelmente é por isso que se observam fluxos de emergência durante o verão após chuvas.
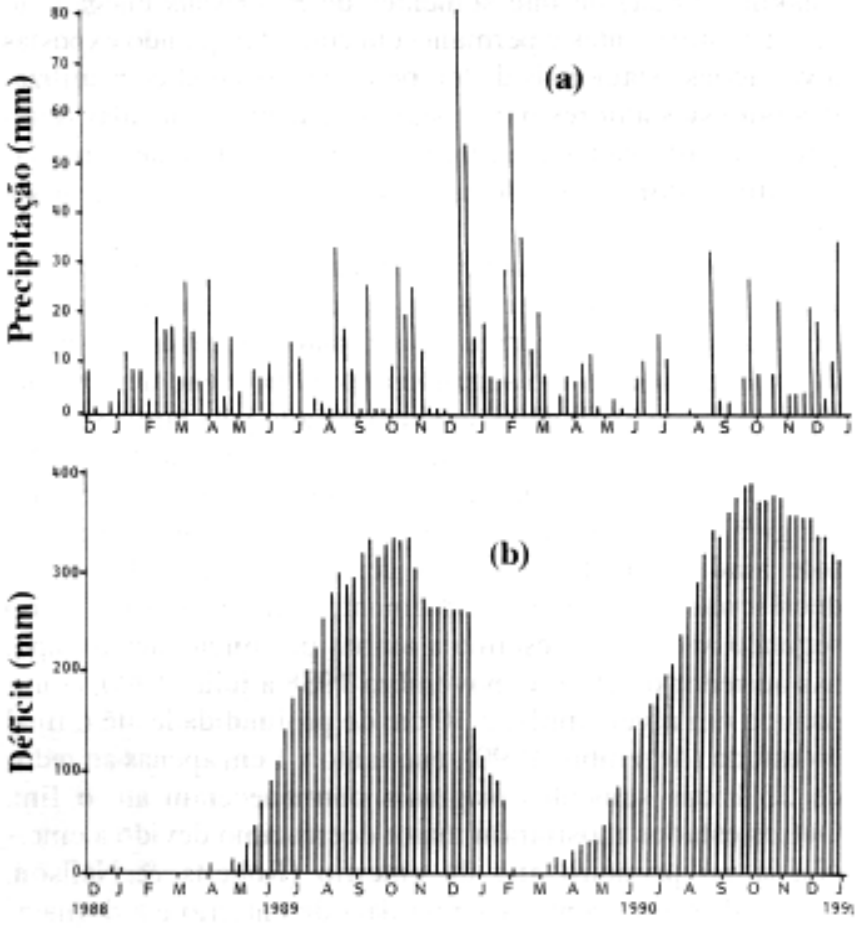

FIG. 5 - Precipitação (a) e déficit (b) de umidade no solo (acumulado) registrados semanalmente no local onde as sementes foram enterradas.

\section{LITERATURA CITADA}

BASKIN, J.M. \& BASKIN, C.C. Does seed dormancy play a role in the germination ecology of Rumex crispus? Weed Science, 33: 340-343, 1985a.

---- The annual dormancy cycle in buried weed seeds: a continuum. Bioscience, 35(8): 492-498, 1985 b.

---- Physiology of dormancy and germination in relation to seed bank ecology. In: Leck, M.A.; Parker, V.T. \& Simpson, R.L., ed., Ecology of Soil Seed Banks. New York, Academic Press, 1989. p.53-55.

BRASIL. Ministério da Agricultura e Reforma Agrária. Regras para análise de sementes. Brasília, SNDA CLAV, 1992. 365p.

CAIXINHAS, M.L. Etudes sur la germination apres enfouissement et les emerences des mauvaises herbes. Proceedíngs EWRS 3 Symposium on Weed Problems in the Mediterranean Area. 1984. p. 63-72.

CARMONA, R. Factors affecting the efficacy of dormancy-relieving chemicals on weed seed banks in the soil. Ph.D. thesis, University of Reading, UK, 1992. 138p.

CARMONA, R. Prolemática e manejo de bancos de sementes de invasoras em solos agrícolas. Planta daninha, 10(1,2): 5-16, 1992.

FOSTER, L. The biology and non-chemical control of dock species Rumex obtusifolius and R. crispus. Biological Agriculture and Horticulture, 6: 11-25, 1989. 
HAND, DJ.; CRAIG, G.; TAKAKI, M. \& KENDRICK, R.E. Interaction of light and temperature on seed germination of Rumex obtusifolius L. Planta, 156: 457460, 1982.

KARSSEN, C.M. Seasonal patterns of dormancy in weed seeds. In: Khan, A.A.,ed., The physiology and biochemistry of seed development, dormancy and germination. New York, Elsevier Biomedical Press, 1982. p.243-270.

KAY, F.F. A soil survey of the University Farm, Sonning, Berks. Bulletin of Faculty of Agriculture and Horticulture- University of Reading, 49, 1936.54 p.

LORENZI, H. Plantas daninhas do Brasil. Terrestres, aquáticas, parasitas, toxicas e medicinais. 2 ed. Nova Odessa, SP, Editora Plantarum Ltda. 1991, 440p.

MURDOCH, A.J. Factors influencing the depletion of annual weed seeds in the soil. Ph.D. thesis, University of Reading, UK, 1982. 222 p.

---- Low-cost, computer-based data handling of soil temperature data in field experiments. Aspects of Applied Biology, 10: 337-341, 1985.

MURDOCH, AJ. \& ALLEN, S. Environmental data logging and control using combine. Proceedings Test + transducer Conference, Wembley, 2: 143-155, 1986.

ROBERTS, E.H. The interaction of environmental factors controlling loss of dormancy in seeds. Annals of Applied Biology, 98: 552-555, 1981.

ROBERTS, E.H. \& TOTTERDELL, S. Seed dormancy in Rumex species in response to environmental factors. Plant, Cell and Environment, 4: 97-106, 1981.
ROBERTS, H.A. \& NEILSON, J.E. Seed survival and periodicity of seedling emergence in some species of Atriplex, Chenopodium, Polygonum and Rumex. Annals of Applied Biology, 94: 111-120, 1980.

TAYLORSON, R.B. \& HENDRICKS, S.B. Phytochrome control of germination of Rumex crispus L. seeds induced by temperature shifts. Plant Physiology, 50: 645648, 1972.

TOTTERDELL, S. A study of dormancy in Rumex crispus L. Ph.D. thesis, University of Reading, UK, 1974. 119 $\mathrm{P}$.

TOTTERDELL, S. \& ROBERTS, E.H. Effects of low temperature on the loss of innate dormancy and the development of induced dormancy in seeds of Rumex $o b$ tusifolius L. and Rum ex crispus L. Plant, Cell \& Environment, 2: 131-138, 1979.

---- Characteristics of alternating temperatures which stimulate loss of dormancy in seeds of Rumex obtusifolius L. and Rumex crispus L. Plant, Cell \& Environment, 3: 3$12,1980$.

VAN ASSCHE, J.A. \& VANLERBERGHE, K.A. The role of temperature on the dormancy cycle of seeds of $R u$ mex obtusifolius L. Functional Ecology, 3: 107-115, 1989.

VINCENT, E.M. \& ROBERTS, E.H. The interaction of light, nitrate and alternating temperature in promoting the germination of dormant seeds of common weed species. Seed Science \& Technology, 5: 659-670, 1977.

VINCENT, E.M. \& CAVERS, P.B. The effects of wetting and drying on the subsequent germination of Rumex crispus. Canadian Journal of Botany, 56: 2207$2217,1978$. 